\title{
O PAPEL DAS COOPERATIVAS NO DESENVOLVIMENTO ECONÔMICO LOCAL: UM ESTUDO DE CASO NA COOPERATIVA COOPERNORTE.
}

Desafios

Artigo Original

Original Article

Artículo Original

Coopernorte Cooperative.

El Papel de las cooperativas e el Desarrollo Económico Local: Un estudio de Caso en la Cooperativa Coopernorte.

\section{Josivaldo Alves da Silva* ${ }^{* 1}$}

${ }^{1}$ Curso de Administração, Universidade Estadual do Tocantins (Unitins), Dianópolis, Tocantins, Brasil.

*Correspondência: Universidade Estadual do Tocantins - Unitins, Praça Aurélio Antônio Araújo, n. 2 - Centro, Dianópolis, Tocantins - CEP:77.300-000.e-mail josivaldoadm@yahoo.com.br.

\section{RESUMO}

Este artigo tem como objetivo comparar as práticas cooperativistas da Cooperativa Agropecuária Tocantinense "Coopernorte" com os componentes teóricos da Nova Economia Institucional (NEI). A pesquisa foi realizada por meio de um estudo qualitativo das práticas de governança com base na percepção dos diretores da cooperativa, com relação às estratégias gerenciais adotadas para o controle dos custos das transações e o estabelecimento dos modos alternativos de organização e de produção, da influência dos arranjos institucionais externos no processamento e comercialização dos produtos, e do ambiente institucional onde ocorrem as relações contratuais da Coopernorte com seus fornecedores de matéria prima e compradores de produtos manufaturados. O método empregado foi investigação bibliográfica e documental, além do estudo de caso. A pesquisa é classificada como qualitativa e o instrumento utilizado foi um questionário com questões abertas, aplicado pessoalmente, ao passo que foram realizadas três visitas a Cooperativa Coopernorte no Município de Paraíso Tocantins. Os principais resultados da investigação foram: A Coopernorte processa diariamente um volume aproximado de 8 mil litros de leite e conta atualmente em seus quadros com 445 associados e 22 colaboradores. Os custos de produção representam $20 \%$ do produto final. A comercialização representa um custo de $5 \%$ a 10\%. O desperdício de matéria prima e produtos acabados chegam a 3\%. A matéria prima é comprada do produtor associado com o prazo de pagamento de 30 dias.

Palavras-chave: Cooperativismo, Nova Economia institucional, Governança.

\section{ABSTRACT}

This article aims to compare the cooperative practices of the Tocantins Agricultural Cooperative, Coopernorte, with the theoretical components of the New Institutional Economy (NIE). The research was carried out through a qualitative study of the governance practices based on the perception of the directors of the cooperative. It was analyzed the management strategies adopted to control transaction costs, the establishment of alternative modes of organization and production. This study also focused on the influence of the external institutional arrangements in the processing and marketing of the products, and on the institutional environment where Coopernortehas contractual relations with suppliers of raw material and buyers of manufactured products. The method used was bibliographic, documentary research as well as the case study. The instrument used in the qualitative research was 
a questionnaire with open questions, applied personally.Three of themwere heldin the CooperativeCoopernorte in the Municipality of Paraíso Tocantins, Tocantins, Brazil. The main results of the investigation showed thatCoopernorte processes a daily volume of approximately 8 thousand liters of milk and it currently has 445 members and 22 employees. The production represents 20\%of the final product cost while the distribution represents a cost of 5\% to $10 \%$. The waste of raw material and finished products reaches $3 \%$. The raw material is purchased from the producers, member of the cooperative, who arepaid within 30days.

Keywords: Cooperativism, New institutional economy, Governance.

\section{RESUMEN}

Este artículo tiene como objetivo comparar las prácticas cooperativistas de la Cooperativa Agropecuaria Tocantinense "Coopernorte" con los componentes teóricos de la Nueva Economía Institucional (NEI). La investigación fue realizada por medio de un estudio cualitativo de las prácticas de gobernanza con base en la percepción de los directores de la cooperativa, con relación a las estrategias gerenciales adoptadas para el control de los costos de las transacciones y el estabelecimiento de los modos alternativos de organización y de producción, de la influencia de los arreglos institucionales externos en el procesamiento y comercialización de los productos, y del ambiente institucional donde ocurren las relaciones contractuales de la Coopernorte con sus proveedores de materia prima y compradores de productos manufacturados. El método empleado fue investigación bibliográfica y documental, además del estudio de caso. La investigación es clasificada como cualitativa y el instrumento utilizado fue un cuestionario con cuestiones abiertas, aplicado personalmente, al paso que fueron realizadas tres visitas a Cooperativa Coopernorte en el Municipio de Paraíso Tocantins. Los principales resultados de la investigación fueron: La Coopernorte procesa diariamente un volumen aproximado de 8 mil litros de leche y cuenta actualmente en sus cuadros con 445 asociados y 22 colaboradores. Los costos de producción representan el $20 \%$ del producto final. La comercialización representa un costo del $5 \%$ al $10 \%$. El desperdicio de materia prima y productos acabados llegan al 3\%. La materia prima es comprada del productor asociado con el plazo de pago de 30 días.

Palabras-clave: Cooperativismo, Nueva Economía institucional, Gobernanza.

\section{INTRODUÇÃO}

O cooperativismo é um modelo de organização social que desempenha um papel multidimensional de fundamental importância para o desenvolvimento local, uma vez que sustentado nos pilares, econômico, social, político e cultural, contribui para a geração e distribuição de renda, de forma justa e igualitária entre seus cooperados.

Além do mais, o cooperativismo é caracterizado como uma atividade organizada que nas suas diversas modalidades, cresce e busca se institucionalizar as relações de trabalho diferente do "sistema de trabalho assalariado" subordinado e dependente, encontrando nesse processo apoios, aliados, incompreensões de segmentos de interesses e obstáculos burocráticos nas diversas instancias do Estado (TESCH, 2000).

Diante desse contexto, as cooperativas são agrupamentos de pessoas de forma organizada que necessitam de subscrição de capital para fortalecer as reservas e aumentar as receitas e assim contribuir para a emancipação dos seus cooperados. Inseridas num ambiente concorrencial em decorrência da globalização dos mercados, as cooperativas dos mais diversos ramos de atividade, na maioria das vezes enfrentam dificuldades para se adequar a dinâmica competitiva imposta pelo mercado que leva estas organizações a estabelecerem estratégias gerenciais que vai da aferição dos custos que são gerados no processo de produção e comercialização dos produtos, a influência dos arranjos institucionais 
externos a organização, e as relações formais e informais que forma o ambiente institucional para a adaptação ao ambiente competitivo.

Nessa perspectiva, permite indagar sobre a possibilidade de aplicação dos componentes da Nova Economia Institucional (NEI) proposto por Douglass North, no contexto da gestão de cooperativas. Para Norte (1991) as Instituições são restrições humanamente concebidas que estruturam as interações políticas, econômicas e sociais. Elas consistem tanto em restrições informais "sanções, tabus, costumes, tradições, e códigos de conduta" quanto em restrições formais, podem-se relacionar as constituições, leis, direitos de propriedade.

Nesse sentido, as cooperativas são regidas por um conjunto de princípios e valores de amplitude internacional, pilares normatizadores do cooperativismo que são ajustados para atender a adversidade cultural de todos os povos que habitam no planeta terra. Estes princípios são ajustados nos Congressos da Aliança Cooperativa InternacionalACI. No Brasil, os fundamentos cooperativistas estão cravados formalmente na Constituição Federal a partir de 1971, com sanção da lei 5764/71. Cumpre ressaltar que esta lei foi hospedada na Carta Magna de 1988.

No entanto, as relações formais e informais que ocorrem no ambiente que as organizações cooperativas estão inseridas, ajuda no funcionamento do sistema econômico, fator preponderante para a transformação dos pequenos e médios municípios em micromercados fornecedores de produtos manufaturados com a utilização da matéria prima e mão de obra local.

A Cooperativa dos Produtores rurais do Norte Goiano Ltda. "Coopernorte". Fundada em 27 de janeiro de 1979, na Cidade de Paraíso do Norte, então norte de Goiás. A iniciativa de criação de cooperativas no norte de Goiás foi consequência de um processo de expansão do cooperativismo que iniciou no sul de partir das décadas de 50, 60 .

Efetivamente, a criação do Estado do Tocantins aconteceu com a promulgação da Constituição Federal de 1988 e, com isso, o sistema de representação do cooperativismo, a Organização das Cooperativas Brasileiras (OCB), também criou uma seção estadual local, separando-se da OCB goiana. Assim, a Coopernorte foi precursora do cooperativismo no Estado do Tocantins. O objetivo deste artigo é comparar as práticas cooperativistas da Cooperativa Agropecuária Tocantinense "Coopernorte" com os componentes teóricos da Nova Economia Institucional (NEI). Esta escolha foi motivada pela curiosidade de se entender como as práticas cooperativistas inter-relacionam com as interações políticas, econômicas e sociais de maneira formal e informal, conforme a perspectiva teórica de Douglass Norte.

Este artigo está estruturado na seguinte ordem: a primeira parte aborda o cooperativismo e o processo de transição do cooperativismo de Goiás para o Estado do Tocantins, ao passo que a segunda seção apresenta a nova economia institucional e seus componentes, fechando a parte conceitual para, posteriormente, expor a metodologia aplicada no trabalho, seguida dos resultados e das considerações finais.

\section{COOPERATIVISMO}

Cooperativismo, enquanto movimento, possui várias definições, porém com poucas variações. Segundo Lacombe (2004), cooperativismo é a doutrina que prega a solução de problemas sociais por indivíduos livres que se encarregariam da gestão da produção e participariam equitativamente dos bens produzidos em comum. 
Para a Organização das Cooperativas Brasileiras-OCB, cooperativismo é um movimento, filosofia de vida e modelo socioeconômico capaz de unir desenvolvimento econômico e bem-estar social. Seus referenciais fundamentais são: participação democrática, solidariedade, independência e autonomia (SINDICATO..., 2013).

Como variável administrativa, é possível afirmar que cooperativa é uma organização de direito privado, formada e dirigida por cooperativados que se reúnem com o objetivo de desenvolver uma atividade econômica de interesse comum dos associados (LACOMBE, 2004).

Assim sendo, cooperativismo é um movimento, filosofia de vida e modelo socioeconômico capaz de unir desenvolvimento econômico e bem-estar social. Seus referenciais fundamentais são: participação democrática, solidariedade, independência e autonomia (OCB, 2013).

O cooperativismo, enquanto organização socioeconômica, não se sustenta sobre uma noção ou teoria social específica, mas sobre um conjunto de ideias e noções tais como: mutualidade, união de esforços, solidariedade, associação entre pessoas em função de objetivos comuns, e não exploração do homem pelo homem, justiça social, democracia e autogestão (SINDICATO..., 2009).

Além da perspectiva apresentada pela OCB, o cooperativismo é o sistema fundamentado na reunião de pessoas e não no capital e visa às necessidades equitativas do grupo e não do lucro; busca prosperidade conjunta, estas diferenças fazem do cooperativismo a alternativa socioeconômica que busca resultados com equilíbrio e justiça entre os participantes por intermédio de fatores associado a valores universais, o cooperativismo se desenvolve independentemente de território, língua, credo ou nacionalidade.

Na mesma seara, Schneider (1999) afirma que cooperar significa agir de forma simultânea e coletivamente com outras pessoas para um mesmo fim, ou seja, trabalhar em comum para o êxito de um mesmo propósito. Na prática, cooperar é um ato colaboração entre pessoas que se unem através da constituição de uma cooperativa com a adesão livre de no mínimo 20 pessoas com interesses comuns, economicamente organizadas de forma democrática permitindo a participação espontânea de todos os seus cooperados.

Por outro lado, Cooperativa é uma organização de pessoas que se baseia em valores de ajuda mútua e responsabilidade, democracia, igualdade, equidade e solidariedade. Seus objetivos econômicos e sociais são comuns a todos os cooperados (SINDICATO..., 2013).

“[..] Cooperativa é uma associação autônoma de pessoas unidas voluntariamente para atender suas necessidades e aspirações econômicas, sociais, culturais comuns por intermédio de uma empresa coletiva democraticamente controlada" (TESCH 2000 p.71).

De maneira idêntica, partindo dos pressupostos apresentado pela OCB (2013), os conceitos que dão a identidade ao cooperativismo são; cooperar significa unir-se a outras pessoas para conjuntamente enfrentar situações adversas. No sentido de transformá-las em oportunidade e bemestar econômico e social, na mesma perspectiva a cooperação constitui-se no método de ação pelo quais os indivíduos ou familiares com interesses comuns constituem um empreendimento, os direitos são todos iguais e o resultado alcançado é repartido somente entre os integrantes, na proporção da participação de cada um. Já os sócios são os indivíduos, profissional, 
produtor de qualquer categoria ou atividade econômica que se associa a uma cooperativa para exercer atividade econômica ou adquirir bens de consumo ou duráveis.

Dessa maneira, o ato cooperativo a e relação jurídica entre a cooperativa e o cooperado. E o ato de trabalho que realizam cooperado e sua cooperativa e entre cooperativas para consecução de objetivos sociais. O seu objeto é a produção de bens e serviços, sua causa e fim, no caso de cooperativa de trabalho é satisfazer uma necessidade de trabalho sob o ponto de vista legal é um ato licito voluntário, que tem por fim imediato estabelecer relações jurídicas cooperativas (TESCH, 2000).

“[...] as cooperativas que são sociedades de pessoas, com forma e natureza jurídica próprias, de natureza civil, não sujeitas à falência, constituídas para prestar serviços aos associados conforme o artigo $4^{\circ}$ da lei $n^{\circ}$ 5.764/71 (BRASIL, 1971).

Nesse sentido, Lacombe (2004) descreve que Cooperativa é uma organização de direito privado, formada e dirigida por cooperativados que, se reúnem com o objetivo de desenvolver uma atividade econômica de interesse comum dos associados.

Em síntese, a ACI (2014), o conceitua cooperativa como uma associação de pessoas que se unem, voluntariamente, para satisfazer aspirações e necessidades econômicas, sociais e culturais comuns, através de uma empresa de propriedade coletiva e democraticamente gerida.

Pode-se afirmar que a trajetória do cooperativismo no Brasil, conta com importantes marcos referenciais, perpassados por momentos que foram destaque em nossa História. Tais marcos encontram-se associados a períodos do Império e da República. No que diz respeito à chegada e consequente adaptação dessa forma de organização do trabalho em nosso país, observa-se que, segundo Singer (2002) e Cançado (2007), isso se deu por intermédio dos imigrantes europeus, nos primórdios do século 20. No seu início, no país, toma a forma de cooperativas de consumo, na cidade, e de cooperativas agropecuárias, no campo.

O cooperativismo brasileiro conquistou sua independência e a promessa de apoio do Estado com a promulgação da nova Constituição Federal, em outubro de 1988, no mesmo contexto do nascimento do Estado do Tocantins. Apenas o ramo crédito continua sendo regulado pelo Estado, via Banco Central do Brasil (PINHO, 2004). Na seção seguinte será apresentado um breve histórico do cooperativismo no Estado de Goiás.

\section{O cooperativismo no Estado de Goiás}

As primeiras iniciativas com propósitos cooperativistas no Estado de Goiás iniciaram-se na década de 40 do século 20 e suas origens estiveram ligadas ao processo de ocupação e expansão da fronteira agrícola, que, por sua vez, vincula-se à política de interiorização do país e de uma nova divisão regional do trabalho com o objetivo de reconstruir uma economia mais voltada para o mercado interno. Esse movimento caracteriza-se pelo alto grau de dependência das cooperativas ao poder público federal e estadual.

Dessa forma, a Constituição do Estado de Goiás, de 1946, em seu artigo 36, estabelecia imunidade tributária para todas as cooperativas. Esta se caracteriza na primeira forma de incentivo do cooperativismo no Estado de Goiás. O fomento das atividades cooperativas, por longo tempo, esteve situado na Secretaria de Agricultura do Estado, através do seu Departamento de Assistência ao Cooperativismo (SINDICATO..., 2009). Essa Secretaria desenvolveu alguns trabalhos de educação cooperativista que resultaram nas primeiras 
cooperativas goianas. Muitas delas nasceram de iniciativas políticas e fortemente atreladas ao Estado.

Nesse sentido, pode-se afirmar que as primeiras experiências cooperativas formais em Goiás aconteceram a partir de 1949 e foram incentivadas pelo governo, que desenvolveu um projeto com objetivo de trazer imigrantes para o Estado, não somente com a intenção de ampliar o povoamento, mas também de incrementar novas técnicas de produção agrícola na região. Nesse contexto, as três primeiras cooperativas em território goiano foram constituídas por imigrantes italianos e poloneses, porém estas organizações tiveram vida curta.

Nas décadas de 50 e 60 foram constituídas várias cooperativas de crédito rural e dos ramos de consumo e agropecuário. Na década de 70 houve nova fase de estruturação do movimento no Estado, quando as cooperativas agrícolas ressurgiram com um novo projeto econômico de organizar a produção de grãos nas terras férteis, principalmente do sul e sudoeste de Goiás, ao passo que, nas demais regiões do Estado, o cooperativismo ligado às atividades agropecuárias não se sustentaram com a mesma força (SINDICATO..., 2009).

Diante desse contexto histórico, é possível perceber que, ainda no início das atividades cooperativistas na região, elas eram fortemente dependentes da ação do Estado. Também que a fragilidade em muitos ramos, confirmada atualmente, já estava presente nas suas primeiras atividades, refletindo tendência que se confirmaria décadas mais tarde, a saber, a agricultura extensiva baseada na monocultura.

O pensamento empresarial-cooperativista nasceu nesse período. O ramo que melhor soube utilizar essa relação, graças à especificidade do seu produto, foi o agropecuário. Vale lembrar que é nesse período, ainda estreitamente ligado ao setor rural, que nascem as cooperativas de eletrificação rural. Infelizmente os demais segmentos do cooperativismo ligados ao consumo, ao crédito e ao ensino, principalmente, não obtiveram as mesmas condições de desenvolvimento (SINDICATO..., 2009, p. 19-20).

Na região norte de Goiás - atualmente Estado do Tocantins - existiam várias cooperativas que tiveram suas atividades iniciadas a partir das décadas de 50, 60 e 80. Essas cooperativas estavam localizadas nas cidades de Alvorada, Araguaçu, Araguatins, Araguacema, Arraias, Araguaína, Augustinópolis, Babaçulândia, Cristalândia, Colinas, Dianópolis, Formoso do Araguaia, Guaraí, Miracema, Natividade, Paraíso, Paranã, Porto Nacional, Tocantinópolis e Xambioá (JUNTA..., 2013). Nesses registros, no entanto, não é possível verificar sua longevidade e produtividade.

\section{O cooperativismo no Estado do Tocantins}

As primeiras iniciativas com o propósito de estruturar o cooperativismo no Estado do Tocantins, foram realizadas no período que vai de $1^{\circ}$ de janeiro a $1^{\circ}$ de setembro de 1989. As cooperativas que funcionavam nos municípios que passaram a pertencer ao recém-criado Estado do Tocantins ficaram vinculadas à OCB do Estado de Goiás, mas em processo de transição.

No mês de setembro de 1989 foi criada a Organização das Cooperativas Brasileiras no Estado do Tocantins - OCB-TO - desvinculada do sistema cooperativista goiano. Ainda naquele mesmo ano, no mês de julho, com a criação da Secretaria da Agricultura, foi instituída a Coordenadoria de Associativismo e Cooperativismo, órgão que tinha como objetivo o de cadastrar, dar apoio técnico na organização e constituição das associações e cooperativas por meio de reuniões e palestras, visitas técnicas, seminários e cursos. 
Esse departamento manteve-se vinculado à estrutura organizacional da referida pasta até $1^{\circ}$ de janeiro de 2011, quando foi transformado na Diretoria de Fomento e Fortalecimento ao Cooperativismo e do Associativismo Rural. Em 5 de agosto de 2013, por meio de uma reforma administrativa, retornou à condição de Coordenadoria (SECRETARIA..., 2013).

Como marco inicial do movimento cooperativista no Estado do Tocantins, pode-se mencionar a realização do $1^{\circ}$ Seminário Tocantinense de Cooperativismo, no ano de 1989, na cidade de Miracema do Tocantins, capital provisória do Estado. Na mesma data foi constituída a Organização das Cooperativas Brasileiras no Estado do Tocantins OCB-TO - com sede em Paraíso do Tocantins (JUNTA..., 2013).

Conforme dados fornecidos pelo SesscoopTO/OCB, cinco cooperativas participaram da fundação da OCB-TO: Cooperativa Agropecuária Tocantinense - Coopernorte, Cooperativa Mista Rural do Vale do Javaés - Cooperjava; Cooperativa Agropecuária Vale do Tocantins Araguaia Ltda. Covale; Cooperativa Agropecuária Fronteira da Amazônia Ltda. - Coopeg, e Cooperativa Mista Agropecuária do Bico do Papagaio Ltda. - Combipa. No final da primeira metade da década de 90, 1994, a OCB-TO transferiu sua sede para Palmas, e teve homologado, pelo Ministério do Trabalho e Emprego, seu processo como entidade sindical. A organização tem por objetivo prestar serviços de interesse das cooperativas registradas, além de exercer a coordenação, organização e a representação sindical desta categoria econômica no Tocantins (SINDICATO..., 2013).

Aproxima-se, nesse ponto, da necessidade de também relacionar os aspectos teóricos e conceituais do cooperativismo com os fundamentos da Nova
Economia Institucional (NEI) e seus componentes teóricos. Levando em conta que, as instituições, o ambiente institucional, teoria do contrato de agência, teoria dos custos de mensuração, a teoria dos custos de transação, e a governança exercem papel de extrema relevância no processo gerencial das organizações cooperativas. Por isso passa-se, a partir deste ponto, a demonstrar os debates em torno das definições acerca daquilo que se entende como Nova Economia Institucional.

\section{A NOVA ECONOMIA INSTITUCIONAL E SEUS COMPONENTES}

A institucionalidade das relações formais e informais como norma estabelecida nas operações de negociações de um mercado caracteriza-se na prática como o cumprimento do verdadeiro papel das instituições no desenvolvimento econômico e progresso social, suas particularidades e características estão ligadas diretamente ao comportamento dos indivíduos envolvidos nas transações comerciais.

Assim, estas instituições possuem um caráter normativo através dos dispositivos que definem num dado momento numa sociedade, o conjunto limitado das alternativas aceitas, fato que estabilizam os padrões de comportamento, limitam as escolhas dos atores e formam uma estrutura de referência no mercado fornecedor ou consumidor.

Conforme o ponto de vista de Bueno (2004), Instituições é o termo genérico que os economistas institucionais utilizam para representar o comportamento regular e padronizado das pessoas em uma sociedade; são as ideias e os valores associados a essas regularidades.

Nesse contexto, as instituições são divididas em dois campos distintos sendo as formais e informais. A instituição formal impõe a obediência 
por meio das leis estabelecidas pelo estado como um conjunto de normas para imprimir direitos e deveres, são as regras do jogo para garantir as relações comerciais e sociais, dirimir conflitos. As instituições informais são regras consolidadas pelo convívio social que se cristalizaram no habito dos componentes de uma sociedade e são respeitadas sem que os indivíduos se deem conta disso, fato que ocorre pela pressão de um grupo social sobre seus membros discriminando ou mesmo punindo quem quebra as regras sem que haja interferência do estado (FIANI, 2011).

No entanto, Bueno (2004) aponta que nos processos históricos de mudanças institucional, as instituições são criadas por meio de complexos processos de negociação entre as partes envolvidas, para reduzir os custos contratuais que surgem quando agentes sujeitos a racionalidade limitada e propensos a agir de forma oportunista associam-se para realizar um empreendimento conjunto.

Em outras palavras, Williamson (1993) conceitua o oportunismo como a ação dos indivíduos na busca do seu auto interesse e parte de um princípio de jogo não cooperativo, onde a informação que um agente possa ter sobre a realidade não acessível a outro.

O tratamento da mudança institucional a partir da racionalidade capitalista requer, por conseguinte, uma integração de elementos oriundos de abordagens institucionalistas, que oferecem uma análise das características dos arranjos institucionais e seus impactos sobre o desempenho das empresas. E uma teoria da concorrência de inspiração schumpeteriana, que tenha como elemento essencial o processo de introdução e difusão de inovações por parte das empresas (PONDÉ, 2005 p.21).

Portanto, conforme a concepção de Bueno (2004) a nova economia institucional (NEI) adota uma perspectiva micro-analítica, que enfatiza as instituições, que regulam transações entre agentes econômicos em nível microeconômico. Diante desse arcabouço teórico, pode-se correlacionar os pressupostos da institucionalidade com a nova economia institucional.

Em outras palavras, a nova economia institucional para entender a negociação significa considerar a firma como um conjunto complexo de contratos provenientes de inúmeras transações que geram custos para seu funcionamento (SANTOS, 2009).

Outrossim, conforme o ponto de vista de Bueno (2004), os desenvolvimentos teóricos obtidos pela nova teoria institucional desdobram-se em duas direções. A primeira é analisar as mudanças no meio ambiente institucional geral das economias, a segunda constitui-se uma interação entre as unidades econômicas nos processos de produção, troca e distribuição, desenvolvem instituições que asseguram a cooperação entre as unidades econômicas nesses processos.

Dessa forma, a nova economia institucional, envolve o conjunto de teorias que relacionam as organizações com o ambiente e as instituições nos seus modelos de funcionamento da economia. Nessa perspectiva, o novo institucionalismo surge como uma reação aos pressupostos neoclássicos relacionados à firma, ao consumidor e consequentemente ao equilíbrio de mercado conforme a visão neoclássica que sustenta que a empresa é otimizadora e indiferente às condições apresentadas pelo ambiente externo (ZYLBERSTAJN, 1995).

Por outro lado, Santos (2009) afirma que o objetivo principal da nova economia institucional é estudar os custos de transação, considerando que os mesmos darão origem a modos alternativos de organização da produção, que alteram a eficiência do sistema econômico assumindo distintas formas de 
estrutura de governança por intermédio do arcabouço analítico institucional.

Bueno (2004) aponta que nova economia institucional, para introduzir a discussão, emerge e se difunde dentro da própria economia com a manifestação dos seguintes elementos: a) as instituições importam quando se trata de explicar os processos econômicos; b) a dinâmica institucional, c) o surgimento e a evolução de instituições são passíveis de teorização devendo por isso ser considerado como um conjunto de parâmetros do sistema econômico.

Assim sendo, Zylberstajn (1995) argumenta que o objetivo fundamental da nova economia institucional, também denominada de economia dos custos de transação. É estudar o custo das transações como o indutor dos modos alternativos de organização da produção governança.

Por outro lado, Bueno (2004) argumenta que a nova economia institucional (NEI) procura explicar: Porque em uma determinada empresa prefere-se, fundindo-se com empresas fornecedoras? Em outras circunstâncias, a mesma, outra pertencente ao mesmo ramo, escolhe terceirizar parte de suas atividades. Portanto, para Coase (1937) apud Costa (2012) um dos marcos para o surgimento da nova economia institucional (NEI) é o fato de o mercado funcionar apenas pelo mecanismo de preço é que a firma é um fator de produção. Diante do exposto, pode-se afirmar há uma correlação intriseca entre a nova economia institucional e o ambiente institucional.

Conforme a concepção de North apud Zylberstajn (1995), as organizações desenvolvem-se dentro de um ambiente institucional refletindo as estratégias dos atores que criam as estruturas políticas, sociais e econômicas limitados pelas regras institucionais, buscando otimizar ou maximizar a sua função ou objetivo.
À medida que as trocas entre agentes econômicos foram-se tornando mais frequentes e complexos aumentou-se a necessidade de institucionalizar o ambiente, com o intuito de elevar a probabilidade de sobrevivência das organizações ao mesmo tempo em que se busca que o sistema de trocas se de uma forma mais harmônica e menos onerosa, resultando na maximização e da satisfação dos agentes econômicos e na aproximação da eficiência econômica (SANTOS, 2009, p.15).

Além do mais, Williamson (1993) conceitua o ambiente institucional como as regras do jogo que promovem o desenvolvimento das atividades econômicas e das ações políticas, legais e sociais, que governam a base da produção, troca e distribuição. Constitui-se num conjunto de normas e regras delimitam as ações estabelecidas pelo homem, disciplinando suas ações com seus semelhantes e na regulamentação das instituições por meio das relações formais e informais.

Por outro lado, Souza (2001) sustenta que à medida que os processos de desenvolvimentos surgem, aparecem às imperfeições de mercados e as diferentes forças interagem através da manifestação dos arranjos políticos e institucionais.

Certamente, a preocupação central está respaldada na garantia constitucional da ordem econômica, valorização do trabalho humano e na livre iniciativa, tem por fim assegurar a todos existência digna, conforme os ditames da justiça social, observados os princípios da propriedade privada e função social da propriedade privada conforme prevê os artigos 170, II e III da Constituição Federal (BRASI, 1988).

Logo, fica evidente que o ambiente institucional na prática incorpora de forma intrínseca as instituições formais e informais. Entretanto, a primeira tem seu ápice na Constituição Federal do Brasil e nas leis promulgadas no âmbito da União, estados e municípios criados com o objetivo de 
regular o mercado. A segunda é constituída de forma espontânea por meio de uma articulação permanente dos atores que interagem no processo de negociação obedecendo à lógica de mercado. Diante desse contexto, pode-se inferir que os pressupostos teóricos do ambiente institucional interrelaciona com a teoria do contrato de agência.

Por consequência, o contrato de agência constitui-se num componente que estabelece as formalizações comerciais que ocorrem no ambiente institucional. Uma vez que, o contrato é um acordo voluntário licito entre duas ou mais pessoas físicas ou jurídicas, que se atribuem direitos e obrigações. $\mathrm{O}$ contrato uma vez assinado pelos contratantes ou seus representantes na forma prevista na legislação, passa a ser um instrumento jurídico que obriga aos contratantes o seu cumprimento (LACOMBE, 2004).

Diante do exposto, o contrato de agência é a formalização de um vinculo específico sem dependência com o objetivo de representar o empresário ou empresa na execução de tarefas que exige habilidades e competências que não estão no alcance do proponente contratante. Dessa forma, o marco legal do contrato de agência está previsto no artigo 710 da lei 10.406/2002 o Código Civil Brasileiro, assim estabelece:

Pelo contrato de agência, uma pessoa assume, em caráter não eventual e sem vínculos de dependência, a obrigação de promover, à conta de outra, mediante retribuição, a realização de certos negócios, em zona determinada, caracterizando-se a distribuição quando o agente tiver à sua disposição a coisa a ser negociada (BRASIL, 2002).

Assim, Figueiredo (2013) adverte que as relações comerciais estabelecidas por meio de contrato de agência surgem interesses particulares dos objetivos do proprietário da empresa, fator que dificulta para o empresário a implementação de um plano de maximização de lucro através de um contrato com um agente.

Na concepção de Jensen (1993) apud Segatto Mendes (2001) a estrutura de contrato das organizações limita aos riscos que se comprometeram a maioria dos agentes ao especificar pagamentos fixos por meio de incentivos intrínsecos de acordo com o desempenho. Estes fatores geram risco residual da diferença entre entradas estatísticas de recursos e pagamentos prometidos pelos agentes e suportado por aqueles que se comprometem.

Em suma, a estrutura dos contratos constituise nos direitos de fluxos de caixa líquidos originários das relações contratuais celebradas é uma ferramenta que controla a movimentação financeira (as entradas e saídas de recursos financeiros), em um período determinado pela organização. Por outro lado, Vieira Sobrinho (2000) conceituam o fluxo de caixa como uma sucessão de recebimentos e de pagamentos em dinheiro previsto para um determinado de tempo estabelecido nos vínculos contratuais firmados pelas organizações. Diante dessas considerações aqui exposto, a teoria do contrato de agencia, relaciona-se com a teoria dos custos da transação.

Por conseguinte, a teoria dos custos de transação constitui-se num componente necessário para a realização de contratos de compra e venda de bens tangíveis e intangíveis, num mercado composto por agentes formalmente independentes (SANDRONI, 1999).

Ainda mais, custo da menor mensuração com base na sustentação teórica de Williamson (2000), tradução nossa, ocorreram avanços no conceito de custos de transação. Mas a sua mensuração torna-se difícil, pelo fato de se tratar de uma deficiência, em parte, suprida pela análise comparativa entre os diferentes modos de governança. 
Conforme os pontos de vistas de Queiroz et al (2006), a mensuração dos custos de transação constitui-se numa relevante lacuna teórica. É uma árdua tarefa, dada à complexidade envolvida, amplitude de conceitos, definição do corte analítico, efeito sinérgico entre custos de transação, custos de produção e ambiente institucional. No entanto, os autores citados afirmam que emerge a possibilidade de se aplicar os preceitos da teoria dos custos de mensuração para a identificação dos mecanismos de governança em sistemas produtivos. Fator que permite considerar a possibilidade de mensuração dos atributos transacionados como variável chave de análise que confere ao estudo das governanças maior simplicidade e aplicabilidade quando comparado à utilização do ativo específico como variável chave de análise.

Para Coase (1937), a teoria dos custos de transação, enfoca a firma denominada empresa como uma estrutura de governança da organização e produção com o objetivo de economizar custos de negociação entre agentes. Estas transações ocorrem em um ambiente institucional estruturado e que as instituições não são neutras e, portanto, interferem nos custos de transação.

Conforme conceito sustentado por Zylberstajn (1995), as transações que ocorrem nas relações econômicas podem ser entendidas como trocas de direitos associadas a bens ou serviços, levando em consideração as estruturas que estabelecem o direito à propriedade nas relações de troca entre os indivíduos, quando se estuda o processo econômico de produção. As transações que ocorrem na sociedade são apenas as manifestações visíveis, relativas aos bens transacionados.

Demsetz (1967), tradução nossa, afirma que para uma transação ocorra no mercado significa que um conjunto de direitos de propriedade foi transacionado. Partindo desse pressuposto, o direito a propriedade que tem o papel de instrumentalizar as relações sociais auxiliando os indivíduos a formar expectativas para interagir com os demais, estes fatores tem a função de auxiliar a ordenação das expectativas criadas na sociedade para lidar com outros agentes.

Além disso, Lacombe (2004) afirma que Custos de transação são os custos incorridos quando a organização transaciona com agentes externos, na compra, venda ou troca de bens e serviços, sem contar os preços pagos e recebidos, incluem impostos no caso de bens e serviços, comissões obtenção de informações, tempo e desgastes com a negociação e a redação dos contratos.

Para Williamson (1993), a construção do modelo neoinstitucionalista ocorre com a junção dos conceitos da racionalidade limitada e oportunismo, que são pressupostos que justificam a existência dos custos de transação. Nessa perspectiva, o mesmo autor aponta que a racionalidade e oportunismo é a causa para as falhas de mercado fatores de fundamental importância na distribuição dos custos de transação na correlação empresa e mercado.

No entanto, Fiani (2011) evidencia que o oportunismo para o custo de transação é a exploração maliciosa das informações que se possui "e que a oura parte da transação ignora" para obtenção de vantagens nas transações por meio da transmissão de informações seletivas distorcidas e realização de falsas promessas.

Diante dessas considerações, racionalidade limitada conforme Simon é uma adequação entre os meios e os fins, embora o homem, no contexto organizacional, seja pretensamente racional, suas ações são restringidas por capacidades cognitivas limitadas e falta de informações completas (SIMON, 1965). 
Contudo, Fiani (2011) ressalta que com o efeito da teoria econômica convencional supõe que os indivíduos possuem a racionalidade substantiva tem a capacidade limitada para acumular, processar e transmitir toda a informação que for necessária para promover as transformações que forem mais interessantes dos seus objetivos. Assim não havendo qualquer impedimento para que a melhor decisão possível seja sempre escolhida.

Diante da discussão exposta, surge a necessidade de também relacionar os aspectos teóricos e conceituais do cooperativismo com a estrutura de governança.

\section{As relações do cooperativismo com a nova economia institucional e a governança}

No ponto de vista de Costa (2012), existe uma complexidade nos relacionamentos entre as cooperativas e cooperados, devido à ampliação das especificidades e dimensões mensuráveis na transação e nas relações contratuais e nos acordos de cooperação.

Nesse sentido, o cooperado, que é o dono da cooperativa e, portanto, o principal, a partir do momento em que faz o contrato com a cooperativa e vende sua produção para ela, passa a ser o agente e a ser monitorado por sua própria cooperativa. Como ele não tem muitos incentivos que podem gerar o controle dos seus ativos transacionados, as relações entre eles ficam em uma situação de desequilíbrio. Assim, o objetivo dos contratos é justamente a busca por esse equilíbrio para evitar o comportamento oportunista, monitoramento das transações e evitar os problemas de Agência (COSTA, 2012, p.62).

Ainda segundo a mesma autora, a estrutura da governança em cooperativas significa tratar estas organizações a partir do enfoque da nova economia institucional buscando sustentação nas teorias dos custos de transação, custos de menor mensuração e contrato de agência. Nesse pressuposto, conforme
Bialoskorski Neto (2004), tanto o papel do cooperado quanto o da cooperativa a partir da visão macroeconômica e da interdependência desenvolvidas pelas partes para atender os critérios de competitividade e dos princípios norteadores da cooperativa.

Nesse sentido, os artigos 47 e 56 da Lei 5.764/71, estabelecem que a cooperativa será administrada por um Conselho de Administração "ou Diretoria" e fiscalizada por um Conselho Fiscal, compostos exclusivamente por associados eleitos pela Assembleia Geral (BRASIL,1971). Nesse ponto, a lei estabelece as regras formais que institucionaliza a gestão das organizações cooperativas, convergem com a perspectiva de Douglass Norte, ao afirmar que as Instituições são restrições humanamente concebidas que estruturam as interações políticas, econômicas e sociais e podem-se relacionar as constituições, leis, direitos de propriedade.

Além disso, partindo do ponto de vista sustentado pelos autores acima citados, a sociedade cooperativa norteia-se pela mútua cooperação de seus integrantes com a finalidade lucrativa. Como também, conforme as concepções de Arruda et al (2008) a governança deve garantir que os recursos sejam empregados de forma eficiente e eficaz na missão, nos objetivos e nas metas da organização, os quais devem garantir os interesses dos acionistas e proprietários e maximizar os resultados econômicos da organização, objetivos estes, que também fazem parte do conceito de controladoria.

Assim sendo, a estrutura organizacional da cooperativa segue um modelo de governança formalizada a partir da deliberação estatutária que trata do ordenamento e reunião de atividades e recursos, que terão com propósito de alcançar os objetivos e resultados estabelecidos, esta estrutura 
terá que ser compatível com os objetivos sociais e estratégias estabelecidas nas assembleias de sócios.

Sobretudo, conforme o Instituto Brasileiro de Governança Corporativa, IBCG (2014) a Governança Corporativa é o sistema pelo qual as organizações são dirigidas, monitoradas e incentivadas, envolvendo as práticas e os relacionamentos entre proprietários, conselho de administração, diretoria e órgãos de controle. No entanto, nas cooperativas a tomada de decisões é mais complexa, pelo maior número de pessoas e porque os interesses comuns devem se sobrepor aos individuais, alicerçados no interesse da maioria e isso torna o processo mais demorado fato que influencia na formatação de um modelo de governança diferente das organizações mercantis.

Desse modo, a legislação que regulamenta as práticas cooperativistas define qual será a estrutura hierárquica de uma sociedade cooperativa. A assembleia geral é o órgão supremo e logo abaixo, num mesmo nível, os conselhos de administração e fiscal. Como a cooperativa é uma empresa coletiva, com muitos proprietários, é imprescindível que sua administração seja transparente. O desenvolvimento da confiança mútua entre os associados e a diretoria só se concretiza quando existe transparência nas ações executivas e nas demonstrações dos resultados econômicos da organização.

Dessa forma, a estrutura de governança é encarregada de organizar os arranjos transacionais e constitui-se na matriz institucional na qual as transações são negociadas e sustentam em três elementos fundamentais que são: mercado, hierarquia e contratos (WILLIAMSON, 1993). Nesse aspecto, a capacidade dos governos e organizações empresariais de alcançarem seus objetivos com a formulação e execução de políticas de forma eficaz, está diretamente ligada ao nível de eficiência que proporciona uma maior credibilidade por reduzir os custos de transação.

Em síntese, Fiani (2011) aponta que a estrutura de governança hierárquica, pode assumir uma adaptação coordenada por meio de esforços, fatores que promovem a redução de custos de transação por meio de transações não antecipadas.

\section{MATERIAIS E MÉTODOS}

Este trabalho, de caráter descritivo e exploratório, está inscrito no paradigma interpretativo. Dessa forma, entende-se que a sociedade é uma construção dos seus membros e a realidade social é formada por ocasiões de interação realizadas pelos atores envolvidos, uma vez que eles são capazes de interpretação e de ações significativas (JONES, 1993; ALENCAR, 2007).

Partindo do já posto, a metodologia escolhida é essencialmente qualitativa, realizada por meio de um estudo de caso e pesquisa documental e bibliográfica e aplicação de questionários. Inicialmente foram realizadas visitas a Cooperativa Coopernorte no Município de Paraíso Tocantins, de forma a identificar pessoas que tivessem participado na gestão dessa cooperativa. Cabe destacar que o período de aplicação dos questionários ocorreu de dezembro de 2014, nas dependências da Coopernorte, o número de entrevistados e a natureza dos questionamentos serão expostos a seguir.

Foram aplicados questionários a gestores da Coopernorte que, por sua vez, optaram por responder em conjunto. $\mathrm{O}$ pesquisador optou por não entrevistar os cooperados da Coopernorte pelo fato do foco da investigação estar relacionado às estratégias de gestão adotadas pelos diretores da cooperativa, a partir da obediência ao conjunto de regras de natureza, política, social e legal que estabelece a base para a produção e comercialização de produtos 
manufaturados, derivados de leite no Município de Paraíso do Tocantins e região.

$\mathrm{Na}$ Coopernorte, foram entrevistados dois diretores que responderam um questionário em conjunto. Os questionários detinham questões norteadoras para levantar informações sobre as práticas gerenciais adotadas na cooperativa relacionados às variáveis a seguir: Os custos das transações e os modos alternativos de organização da produção da Coopernorte. A influência dos arranjos institucionais externos da Coopernorte no processamento e comercialização dos produtos. O ambiente institucional onde ocorrem as transações da Coopernorte.

A escolha desses respondentes deu-se pelo papel privilegiado que tiveram no processo de planejamento e gestão na Coopernorte, de forma que os resultados desta pesquisa possam apresentar um bom panorama dos resultados desse conjunto de ações. Somadas a essas ações, foram realizadas consultas a documentos internos da Coopernorte de diversas tipologias, no mês de dezembro de 2014, agrupados da seguinte maneira: 1) Atas de reuniões da Coopernorte; 2) Projetos e Relatórios de gestão.

Ao apresentar os resultados de seleção de documentos, consideram-se o contexto de sua escrita, as relações hierárquicas administrativas que os geraram, bem como sua análise a partir do referencial teórico a que se propõe seguir. Sendo assim, pode-se afirmar neste trabalho que o papel da Cooperativa Coopernorte no desenvolvimento local de Paraíso Tocantins, foi analisado a partir da correlação dos aspectos teóricos e conceituais do cooperativismo com os fundamentos da Nova Economia Institucional (NEI) e seus componentes teóricos "instituições, ambiente institucional, teoria da agência, teoria dos custos de mensuração, teoria dos custos de transação, e governança".

\section{Um breve histórico da Cooperativa Coopernorte}

A Cooperativa dos Produtores rurais do Norte Goiano Ltda. Teve sua fundação em 27 de janeiro de 1979, com o objetivo de atender a uma demanda de serviços de secagem e armazenagens de grãos, tendo em vista que neste período havia uma grande deficiência de armazéns na região de Paraíso então Norte de Goiás.

Com a criação do Estado do Tocantins em 05 de outubro de 1988, estatuto social foi alterado denominando a razão social para Cooperativa Agropecuária Tocantinense Ltda. "Coopernorte" produtos CAT e passou a atuar na produção de leite, manteiga, queijo, ração e sal mineral.

Em 1991, deu-se inicio a construção do laticínio, sendo inaugurado em 15 de setembro 1992. A Coopernorte recebe diariamente um volume aproximado de 8 mil litros de leite, sendo que no período de seca reduz para 6 mil litros a capacidade atual suporta a armazenagem de 30 mil litros de leite ao dia.

Atualmente a Coopernorte conta nos seus quadros com 445 associados e 22 colaboradores, que trabalham em regime de cooperação para a produção de leite pasteurizado tipo " $\mathrm{C}$ " queijo mussarela e manteiga de Leite. Os principais mercados consumidores dos produtos CAT são: Paraíso do Tocantins, Palmas e região, Porto nacional, São Paulo e alguns Estados do Nordeste do Brasil.

Em síntese, o mercado fornecedor da matéria prima para a Coopernorte, são os municípios de: Paraíso do Tocantins, Barrolândia, Miranorte, Miracema, Divinópolis, Marianòpolis, Monte Santo, Chapada de Areia, Rosalândia, Fátima, Pugmil e Oliveira de Fátima, somando um total de 77 fornecedores de leite, sendo parte deles sócios da cooperativa (COOPERNORTE, 2014). 
Portanto, diante desse contexto histórico pode-se perceber que ao longo de 35 anos de existência, a Coopernorte atua de forma interrupta na produção e comercialização de derivados de leite na região de Paraíso do Tocantins, esta longevidade pode estar relacionada a decisões conscientes de suas diretorias em relação à iniciativa de empreender por meio de boas práticas de inovação combinada com estratégia de mercado, a provisão de pessoas qualificadas e a gestão adequada de conflitos internos e externos. Estes fatores combinam com definição clássica de Douglass Norte, uma boa relação dos arranjos institucional local contribui para um bom ambiente econômico.

\section{RESULTADOS E DISCUSSÃO}

Partindo das questões já apresentadas, procurou-se averiguar os resultados alcançados das práticas cooperativistas estabelecidas pela Coopernorte, de forma a permitir entender o contexto do ambiente institucional, por consequência das ações com base nos fundamentos da Nova Economia Institucional.

No entanto, com a realização desta pesquisa na Coopernorte, constataram-se vários aspectos importantes, os principais resultados obtidos com a pesquisa estão ilustrados nas citações transcritas do questionário aplicado, conforme respostas a seguir.

Sobre como se deu o processo de mensuração dos custos das transações e dos modos alternativos de organização da produção, os diretores da Coopernorte emitiram a seguinte opinião:

[...] os custos de produção da cooperativa representam 20\%. A comercialização representa de $5 \%$ a $10 \%$. O desperdício de matéria prima e produtos acabados chegam a $3 \%$ [...] ( COOPERNORTE, 2014).

Em relação aos procedimentos adotados pela Coopernorte para medir os custos gerados com pagamento de comissões sobre vendas, obtenção de informações, tempo e desgastes com a negociação e elaboração dos contratos, os diretores assim opinaram:

[...] é feito de forma terceirizada sendo pago $10 \%$ sobre a venda do leite e $5 \%$ sobre os derivados, manteiga, mussarela e leite pasteurizado [...] ( COOPERNORTE, 2014).

Sobre como se procede às relações econômicas da Coopernorte com os parceiros seus e fornecedores, os diretores assim se manifestaram:

A matéria prima é comprada do produtor associado com o prazo de pagamento de 30 dias. Os produtos são vendidos com prazo de 08 dias para pagamento. Não é permitido desconto o preço é padronizado (COOPERNORTE, 2014).

Sobre a influência dos arranjos institucionais externos da Coopernorte no processamento e comercialização dos produtos. A Coopernorte estabelece alguma estratégia para redução dos custos de produção a fim de alcançar um diferencial competitivo sobre seus concorrentes, os gestores assim opinaram:

[...] A Coopernorte estabelece o limite de $20 \%$ para a redução dos custos de produção [...] (COOPERNORTE, 2014).

Sobre quais são as regras especificas que o mercado exige para Coopernorte colocar seus produtos no mercado, os diretores emitiram a seguinte opinião:

[...] É feito o serviço de inspeção estadual, SIE decreto 343/96, selo de qualidade ADAPEC/TO [...]. (COOPERNORTE, 2014).

Em relação os fatores econômicos que influenciam diretamente na formação dos preços dos produtos Coopernorte, os diretores assim se manifestaram: 
[...] Influencia na aquisição da matéria prima, custo do frete, pois tem fornecedores de outros municípios [...] (COOPERNORTE, 2014).

Sobre o ambiente institucional onde ocorrem as transações. Como se dá as relações comerciais formais e informais envolvendo a Cooperante e seus fornecedores, os diretores assim se manifestaram:

\begin{abstract}
A Cooperativa efetua suas compras exclusivas dos associados, o vinculo formal é a associação à cooperativa e a emissão de nota fiscal sendo permitido o adiantamento de pagamento por meio de contrato. É constante a dificuldade para a formalização dos contratos pelo fato da oscilação da produção. É realizado o sistema de troca de matéria prima (leite) por produtos do supermercado da cooperativa que dispõe de sal mineral, ração e secos e molhados (COOPERNORTE, 2014).
\end{abstract}

Sobre como procedem às relações institucional envolvendo a Coopenorte e seus cooperados, os diretores assim opinaram:

[...] É realizado assembleia geral uma vez por ano, assembleia geral extraordinária, reuniões nas fazendas para apresentar as demandas [...] (COOPERNORTE, 2014).

No tocante aos critérios que a Coopernorte estabelece para compra e venda com relação a preço e condições de pagamento, os gestores assim manifestaram:

[...] A mudança de preço é informada ao associado no prazo de 10 a 15 dias, exige inspeção da qualidade do leite, pontualidade na entrega. O serviço de coleta é feito pela própria cooperativa entorno de $80 \%$ do leite [...] (COOPERNORTE, 2014).

Sobre as normas estabelecidas pela Coopernorte para a produção, troca e distribuição de seus produtos, os diretores assim opinaram:

[...] Obedece ao Padrão de qualidade selo de inspeção ADAPEC SIE 084, Contrato com distribuidores [...] (COOPERNORTE, 2014).
Sobre como se dá fiscalização da Coopernorte os modos e meios e o local de produção da matéria prima fornecida pelos seus fornecedores, os gestores assim se manifestaram:

[...] É realizado o teste de qualidade onde é identificada a qualidade do leite [...] (COOPERNORTE, 2014).

Sobre se a Coopernorte exige dos seus fornecedores de matéria prima a sua legalização junto aos órgãos competentes (vigilância sanitária, certificado ADAPEC), os diretores assim opinaram:

[...] A exigência é feita no ato da formalização do contrato é exigido o certificado de vacina do rebanho [...] (COOPERNORTE, 2014).

Analisando esses resultados a luz do conceito da Nova Economia Institucional e seus componentes. Pode-se inferir que a Coopernorte adota como regra e modelo de gestão na execução das ações operacionais de forma sistematizada, utilizando como parâmetro a pratica dos princípios cooperativistas como meio para manter as relações formais e informais com seus os cooperados e fornecedores, através de um processo permanente de negociação entre as partes interessadas.

Nota-se que a Coopernorte, promove uma constante interação com o ambiente externo a partir da capacidade produtiva interna convergindo através de atos cooperativos e adquirindo forças competitivas de mercado, por meio do controle sistemático dos custos de transação praticados como forma de governança cooperativa.

Outros fatores considerados, são as relações do cooperativismo com os pressupostos da Nova Economia Institucional (NEI), percebe-se que a Coopernorte mostra capacidade para entender e gerenciar a complexidade das relações entre a 
cooperativa e seus cooperados e colaboradores e responder de forma rápida as expectativas do público externo, que são; um conjunto de indivíduos segmentados por interesses comuns em relação à sociedade, e que, possam estar ligados à cooperativa de forma direta ou indiretamente, empresas, instituições públicas e organizações do terceiro setor.

Entretanto, vale ressaltar que as informações levantadas na pesquisa, mostram que a Coopernorte, adota como estratégia para a redução de custos com as transações e diminuição do tempo da compra da matéria prima, transformação até o consumidor final. Estas ações ocorrem por meio de formulação de parcerias e celebração de contratos com fornecedores da matéria prima, prestadores de serviços e clientes, limitando os riscos para os cooperados possibilitando a manutenção de um fluxo de caixa sustentável, fatores que proporcionam a institucionalização do ambiente e longevidade da cooperativa e das organizações parceiras.

Pode-se concluir que o modelo teórico proposto neste trabalho a partir do institucionalismo de Douglass North, é suficiente para explicar o desempenho da Coopernorte. Com base nas relações formais e informais praticadas no cumprimento da missão, um fator de fundamental importância para a criação de um ambiente institucional capaz de sustentar as estratégias de ação e sobrevivência da Cooperativa.

\section{CONCLUSÃO}

Concluindo o artigo, retoma-se o objetivo, que foi o de comparar as práticas cooperativistas da Cooperativa Agropecuária Tocantinense "Coopernorte" com os componentes teóricos da Nova Economia Institucional (NEI). Foram identificados e selecionados cinco componentes que correlacionam à nova economia institucional com as práticas cooperativistas da Coopernorte: 1) As instituições e o ambiente institucional; 2) Teoria do contrato de agência; 3) Teoria dos custos de mensuração; 4) Teoria dos custos de transação; 5) Governança.

O primeiro representa os níveis de atuação da organização do sistema econômico e promoção do desenvolvimento de maneira geral. $\mathrm{O}$ segundo tratase das formalizações comerciais que ocorrem no ambiente institucional. $\mathrm{O}$ terceiro determina que a mensuração dos custos de produção de qualquer bem ou serviços na economia sejam determinados pelos conhecimentos tecnológicos que a organização dispõe. No quarto componente, os custos gerados para firmar contratos de longo prazo em ambiente de incertezas. Por ultimo, as estruturas institucionais necessárias para se organizar as transações no sistema econômico.

$\mathrm{Na}$ opinião do autor deste trabalho, um dos motivos da aproximação das práticas cooperativistas com os componentes da nova economia institucional identificado na pesquisa, se deu pelo fato do modelo de gestão das cooperativas serem essencialmente diferentes da administração tradicional. A gestão cooperativista é sustentada nas normas estatutárias, princípios e valores universais e legislação específica. Ao contrário do que preconizam a gestão privada.

Todos os autores declararam não haver qualquer potencial conflito de interesses referente a este artigo.

\section{REFERÊNCIAS}

ACI - ALIANÇA COOPERATIVA INTERNACIONAL. Co-operative: identidade, valores e princípios. Disponível em < http://ica.coop/en/whats-co-op/co-operative-identityvalues-principles>. Acesso em 20 nov. 2014.

ADAPEC, Agência de Defesa Agropecuária do Tocantins. Diretoria de Inspeção e Sanidade Animal. Mensagem recebida por Josivaldo Alves da Silva < josivaldoadm @ Yahoo.com. br $>22$ de jan. 2015. 
ARRUDA, de Silva Giovana; Madruga, Rossi Sérgio; Junior Freitas de, Izaguirry Ney: a governança corporativa e a teoria da agência em consonância com a controladoria: revista de administração da UFSM Santa Maria, v. I, N.1 p. 71-84, JAN/ ABR 2008.

ALENCAR, E. Pesquisa em turismo. Lavras: Ufla; Faepe, 2007. 174p.

BIALOSKORSKI NETO, S. Cooperativismo é Economia Social. III Seminário Tendências do Cooperativismo Contemporâneo, 13. Cuiabá, 2004. Disponível em: http//www.ocb.org.br.Acesso em: 30 de set.2017.

BUENO, Paulo Newton: A lógica da ação coletiva, Instituições e crescimento, uma resenha temática sobre a nova economia institucional: revista economia, Brasília (DF), V, 5 n,2 p.361-420 JUL/DEZ. 2004 em www.anpec.org.br/revista acesso em 26 de Setembro de 2013.

BRASIL. Constituição da República Federativa do Brasil de 1988. Brasília DF; Senado Federal: Centro Gráfico, 2014a, 292p.

- Ministério da Agricultura, Pecuária e Abastecimento. Evolução do cooperativismo no Brasil: Denacoop em ação. Brasília: Ministério da Agricultura, Pecuária e Abastecimento, Mapa, 2006. 124p.

Lei $n^{o} 5764$ de 16 de dezembro de 1971. Disponível em < http://www.planalto.gov.br/ccivil_03/leis/15764.htm> . Acesso em: 30 dez. 2014c

, Código Civil Brasileiro Lei 10.406 de 10 de janeiro de 2002. Presidência da República, Casa Civil, Subchefia para Assuntos Jurídicos. Disponível em http://www.planalto.gov.br. Acesso em 4 de jan. de 2016.

COSTA, da Curta Lourdes de Danielle: As relações contratuais entre as estruturas cooperativas: um estudo em sistemas agroindustriais suinicolas; Dissertação de Mestrado da Universidade estadual de Maringá- Maringá 2012, 181 p.

COOPERNORTE, Cooperativa Agropecuária Tocantinense, Rodovia BR 153- KM 492, Zona Rural-Paraíso do Tocantins CEP -77.600-000 (63) 3602-1620 email produtoscat@uol.com.br. Questionário respondido para esta pesquisa. 2014.
,Cooperativa Agropecuária

Tocantinense, COOPERNORTE. Manual do Cooperado. Palmas-TO, SESCOOP/TO, 2012, 48, p.

COASE, R. H. (1937). The Nature of the Firm. Economica, Vol. 4, November, pp. 386-405.

DEMSETZ, Harald, a teory of property rights. American economic reviw. Papers and proceedigs, v,57, n,2, p.347-359, 1967.

FIANI, Ronaldo. Cooperação e Conflito: Instituições $e$ Desenvolvimento Econômico. Rio de Janeiro: Elsevier, 2011 $238 \mathrm{p}$.

FIGUEIREDO, Felipe Guerra de. Nova economia institucional e o setor sucroenergético brasileiro: análise das medidas intervencionistas no setor sob a ótica da teoria da agência positiva. Dissertação de mestrado da Universidade Federal do Rio de Janeiro, 2013,87p. Disponível em http://www.ie.ufrj.br/posgraduçao/Felipe guerra Figueiredo.pff. Acesso em 3 de jan.2016.

IBCG. Instituto Brasileiro de Governança Corporativa. http://www.ibgc.org.br/index.php. Acesso em 22 de Janeiro de 2014.

JENSEN, M.; MECKLING, W. Theory of the firm: managerial behavior, agency costs and ownership structure. Journal of Financial Economics, v. 3, n. 4, p. 305-360, 1976.

JONES, P. Studying society: sociological theories and research pratices. London: Colins Educational, 1993.

JUNTA COMERCIAL DO ESTADO DO TOCANTINS (Jucetins). Sistema Nacional de Registro de Empresas - Sinrem. Palmas-TO, 2013

LACOMBE, Francisco José Masset. Dicionário de Administração. São Paulo: Saraiva, 2004,263p.

NORTH, D. C. (1991). Institutions, Institutional Change, and Economic Performance. Cambridge: Cambridge University Press.

OCB - SINDICATO E ORGANIZAÇÃO DAS COOPERATIVAS BRASILEIRAS. Principios Cooperativistas: sete linhas orientam o cooperativismo. Disponível em: <http://www.ocb.org.br/site/cooperativismo/principio s.asp>. Acesso em: 11 jun. 2013.

PINHO, D. B. Cooperativismo no Brasil: da vertente pioneira à vertente solidária. São Paulo: Saraiva, 2004. 357p. 
PONDÉ, João Luis S.P de Souza: o processo de seleção, custo de transação e a evolução das estruturas empresariais: Tese de Doutoramento, Instituto de Economia-UNICAMP-Campinas SP2000, 162 p.

João Luis S.P de Souza: Instituições $e$ Mudança Institucional: uma Abordagem Schumpeteriana. Revista Economia, 2005, 25, p.

SANTOS, Selma Regina Simões. A Nova Economia Institucional. Universidade Federal de São Carlos e Faculdades Integradas Claretianas de Rio Claro, 2009.

SEGATTO-MENDES, Andrea Paula. Teoria $d a$ agência aplicada a análise de relações entre participantes dos processos de cooperação tecnológica universidade - empresa (online). São Paulo: Faculdade de economia, Administração e Contabilidade, Universidade de São Paulo, 2001. Tese de Doutorado em administração. Acesso em 22/01/2014. Disponível em: http://www.teses.usp.br/teses.

SECRETARIA DA AGRICULTURA E PECUÁRIA DO ESTADO DO TOCANTINS (Seagro-TO). Diretoria de fomento e fortalecimento ao cooperativismo e do associativismo rural. PalmasTO: Seagro, 2013.

SADRONI, Paulo: Novíssimo dicionário de economia: Ed- BESTE SELLER, uma divisão do circulo do livro São Paulo 1999, 650, p.

SIMON, H. A. Comportamento administrativo: estudo dos processos decisórios nas organizações administrativas. 2.ed. Rio de Janeiro: Fundação Getúlio Vargas, 1965.

SCHNEIDER, J. O. - Democracia-participação $e$ autonomia cooperativista/ José Odelso Schneider. 2. ed.São Leopoldo: UNISÍNOS, 1999, 495p.
SINDICATO E ORGANIZAÇÃO DAS

COOPERATIVAS BRASILEIRAS NO ESTADO

DO TOCANTINS (Sescoop-TO/OCB, 2013).

SINDICATO E ORGANIZAÇÃO DAS COOPERATIVAS BRASILEIRAS NO ESTADO DE GOIÁS (OCB-GO). Cooperativismo passo a passo. 8. ed., Goiânia: OCB-GO, 2009. 49 p.

SOUZA, Nali de Jesus de: Desenvolvimento econômico. 5 - ed reimpressão São Paulo Atlas 2011, $313 \mathrm{p}$.

QUEIROZ, Silvia Morales de, etal. Grupo de Pesquisa: Sistemas Agroindustriais e Cadeias Produtivas. XLIV CONGRESSO DA SOBER, Fortaleza, 23 a 27 de Julho de 2006. Disponível em http://www.sober.org.br. Acesso em 3 de jan.2016.

TESCH, Walter. Dicionário básico de cooperativismo. Brasília: Sescoop, 2000. 286p.

TOCANTINS. DECRETO $\mathrm{N}^{\circ} 343$, de 4 de novembro de 1996. Estatui a regulamentação da Inspeção e Reinspeção Industrial e Sanitária de Produtos de Origem Animal, 178, p.

VIEIRA SOBRINHO, José Dutra: Matemática 69 financeira: 7ed - São Paulo: Atlas 2000, 409 p.

ZYLBERSTAJN, Décio. Estruturas de governança e coordenação do agrobusiness: Uma aplicação da nova economia das instituições. USP, São Paulo, 1995.

WILLIAMSON, O. E. (1993). "Transaction Cost Economics and Organization Theory",Industrial and Corporate Change, Vol. 2, n 2, pp 107.156. 